\title{
CHANGES IN BASAL SALIVARY CORTISOL LEVEL IN PRETERM VERSUS FULL-TERM BABIES IN THE FIRST YEAR OF LIFE. POSSIBLE LINKS TO SELF-REGULATION
}

G. Kmita ${ }^{1,2}$, E. Kiepura ${ }^{2}$, W.L. Dragan ${ }^{1}$, A. Kunkiewicz ${ }^{2}$, M. Oltarzewski ${ }^{2}$, B. Cieslak-Osik ${ }^{3}$, W. Urmanska ${ }^{2}$, D. Lewandowska ${ }^{2}$

${ }^{I}$ Department of Psychology, University of Warsaw, ${ }^{2}$ Institute of Mother and Child, ${ }^{3}$ Hospital "Karowa", Warsaw Medical University, Warsaw, Poland

Background and aims: Grunau and colleagues (2007) describe the phenomenon of altered basal salivary cortisol levels in the case of the tiniest preterm babies in the first 18 months of life which may suggest a disregulation of the HPA-axis and early programming of stress response. This in turn may have important implications for child's behavioral development and self-regulation. The study was aimed at evaluating early trajectories of cortisol levels in preterm infants as compared with full-term ones and looking for possible links to child's behavioral strategies of self-regulation.

Methods: 95 families participated in the study, 33 with babies born before $29^{\text {th }}$ gestational week, 31 between 29 th and $34^{\text {th }}$ week and 31 - at term. Salivary cortisol samples were collected using a small cotton dental roll, between 8:30 and 11:00, at the age of 1,3,6 and 12 months (corrected age in the case of preterm infants). No stimulant was used. Cortisol was assayed with "Cortisol ELISA" -IBL International GmbH no cat::RE52611. Behavioral data were also prospectively video-recorded. Child's developmental status, biological risk factors, socio-economic variables, temperament and parental depression were controlled for. The study was conducted as a part of a larger project on the relational and biological predictors of selfregulatory processes in preterm children.

Results and conclusions: Cortisol levels in the three groups at the age of 1, 3,6 and 12 months will be compared. A preliminary analysis of the relationships between cortisol trajectories and early self-regulatory strategies will be presented and discussed. 